\title{
The Aesthetic Features of Fifth Erhu Rhapsody
}

\author{
Wang Juanjuan', Li Jia ${ }^{2, *}$ \\ ${ }^{1}$ College of Music, Qingdao University, Qingdao, Shandong, China \\ ${ }^{2}$ College of Music, Shanxi Normal University, Taiyuan, Shanxi, China \\ Corresponding author
}

Keywords: Aesthetics, Performance Aesthetics, Erhu Rhapsody, Wang Jianmin

\begin{abstract}
Wang Jianmin's five "Erhu Rhapsody" are milestone works in contemporary erhu creation. He incorporates the creative concept of "the combination of Chinese and Western, and the appreciation of elegance and popular" into modern erhu works, making his works have a high degree of artistic and academic value. With his profound melody creation skills, he created beautiful melodies, which won unanimous praise and high praise from the audience in aesthetic appreciation. His works draw lessons from Western composing techniques and genres and make innovations on this basis, incorporating national styles and structural elements of national music, making national music available to the world in a brand-new way. Mr. Wang Jianmin strives for perfection, perseverance, and breakthrough in his creative career. He has a good grasp of the degree of innovation in all angles of the work, and strives to promote skills with music, designing the difficulty and skills of the work from the perspective of the composer, and then practicing it through performance, Promotion, announced the development of erhu performance and the discipline of erhu. This article will conduct a systematic aesthetic analysis of the five "Erhu Rhapsody" from the perspective of music aesthetics, the logical thinking mode of music philosophy, and take "The Fifth Erhu Rhapsody" as an example, to explore the aesthetic characteristics of Mr. Wang Jianmin's five Rhapsody.
\end{abstract}

\section{Introduction}

The reshaping of music performance refers to the completion of the sound shaping according to the requirements of the work. It requires the performer to study and analyze the music score carefully, understand the background of the times generated by the music score, the emotional life of the composer, and the creative style, and fully grasp the situation. The requirements of the work in terms of expression form and spiritual connotation, so as to follow the instructions of the music score and the wishes of the composer to explain the creative concept and intention of the work.

\section{Creativity of Music Performance}

The creativity of music performance means that on the basis of respecting the intentions of the composer, the performer is still an individual with subjective inclination and personal aesthetic orientation and interest. In the process of interpretation, it is bound to bring personal life experience and emotions. Experience, integrate into the spiritual temperament of the time you live in, so as to 
understand and interpret the works with personal aesthetic ideals and concepts, and form a personal style. It can be said that the artist's personal style is a sign that the artist's artistic attainments have reached a mature stage. Generally speaking, artistic creation begins with imitation. Imitation is necessary as the primary stage of learning. However, with the deepening of learning, artists have gradually poured more and more self-awareness, and this self-awareness will be reflected in musical performances. middle. The American poet Whitman once said eloquently: "You must understand that in your work, there is no possibility of features that you don't have. "This is from the perspective of creation reveals that artists will bring their various character traits to their own artistic creation. From the perspective of performance creation, the interpretation behavior of performing artists is also a creative behavior. They will not only put themselves Bringing various personality traits into his own performances, and even bringing habitual movements and expressions in his daily life into his performances, becoming some habitual gestures. The creativity of music performance is also concentrated in the performance of the artist Style. Performance style is a very comprehensive high-level concept; it is the embodiment of the artist's overall artistic charm and overall personality. It can not only be expressed in some external body language (posture) and movement expressions, but also in The artist projects mature inner expressive intentions and motivations into the details of musical works. From every paragraph, every phrase, and even the time value and intensity of every note, it exudes a unique effect. . Music performance style is a unique characteristic of a person, it is difficult to imitate, its imitation can only be used to imitation, it is bound to be unsatisfactory. Therefore, a mature performance artist usually does not imitate other artists to form one's own personal style.

The reshaping and creativity of music performance are complementary to each other. Remodeling is not mechanically restored, nor can it be mechanically restored. Remodeling is creatively remodeling; creativity is not completely free to play and do whatever you want, but is based on remodeling, and is based on remodeling. The important nature of music performance is its own meaning as a second creation. The complementary relationship of remodeling and creativity together constitutes an important principle of musical performance interpretation: faithfulness to the original work and the unity of performance creation, the unity of historical style and the spirit of the times. How to unify must be balanced by the performing artist. Earlier, from the artistic nature of music performance, it was mentioned that the meaning of music performance is to provide listeners with spiritual enjoyment through emotional and aesthetic performance.

\section{The Aesthetic Interpretation of Erhu Rhapsody Series}

Erhu is one of the most popular and influential national musical instruments in our country. It is different from Western string music; the sound is mellow, soft, and a bit bleak. As a national musical instrument, the erhu is saturated with national aesthetic emotions, and its repertoire tends to express lingering and sad emotions. With the development of the times, the aesthetic taste of human beauty is constantly changing, especially under the influence of Western civilization; the aesthetic concept of the Chinese has undergone tremendous changes. How the erhu adapts to this change is a difficult problem for erhu artists.

The outstanding erhu artist Liu Tianhua took the lead in transforming the erhu, not only changed the erhu tuning and performance techniques, greatly enhanced the expressive power of the erhu, but also created some works with modern aesthetic spirit. For example, "Bright Walk", etc., deeply changed people's aesthetic expectations for the erhu art, and made people realize that the erhu, a national folk instrument, can also express modern aesthetic emotions and aesthetic concepts. On the road of erhu art pursuing aesthetic modernity, Mr. Wang Jianmin's five erhu rhapsody undoubtedly push the erhu art to a new realm and a new height. Whether it is in terms of musical structure, mode 
and language, or in the selection, extraction, and reorganization of materials and tones, Mr. Wang Jianmin not only uses elements of national music appropriately, and strives to highlight certain characteristics of national music, but also strives to pursue the art of erhu. Constantly innovate, strive to combine tradition and modernity, nationality and globality, and consciously pursue the aesthetic modernity of erhu art.

The five "Erhu Rhapsody" are milestone works in contemporary erhu creation. Mr. Wang Jianmin has incorporated the creative concept of "the combination of Chinese and Western styles, and the appreciation of elegance and commonplace" into his works, making his works possess a high degree of artistic and academic value, and also rely on His profound melody creation skills, creating beautiful and pleasant melody, won the audience's unanimous praise and high praise in aesthetic appreciation. His works draw lessons from Western composition techniques and genres, and on this basis to innovate, incorporate national styles and structural elements of national music. Make national music available to the world in a brand new way.

Mr. Wang Jianmin used his unique vision to discover the connection between the characteristics of Rhapsody's multi-section style and the characteristics of the Chinese multi-section style ensemble circulatory style. He combined it with innovation and grafted the genre of Rhapsody with Chinese folk music. This breakthrough raised the level of the art of erhu performance. , Demonstrated the grandeur of Chinese music, promoted the development of erhu performance art, and made great contributions to the development of Chinese folk music. Mr. Qiao Jianzhong said: "Wang Jianmin used brand-new vocabulary and techniques to overturn the original thinking mode of erhu music creation and opened up a new context for erhu music, a distinctive symbol of modernity exploration." Mr. Wang Jianmin has been striving for perfection, perseverance, and breakthrough in his creative career, and he has a good grasp of the degree of innovation in all angles of the work, and strives to promote the difficulty and skill of designing works from the perspective of the composer with music. And so on, and then practiced and promoted through performance, which promoted the development of erhu performance and the discipline of erhu.

\section{Aesthetic interpretation of creative background}

Mr. Wang Jianmin is a very representative composer in contemporary Chinese national instrumental music creation. Since the publication of "The First Erhu Rhapsody" in 1988, he has worked hard for more than 30 years. Among them, the five "Erhu Rhapsody" have always been famous for their colorful modes, tonality changes and collisions, and difficult performance techniques. Among the large number of outstanding works created by him, "Erhu Rhapsody" is regarded as a rather special "phenomenal" creation. Now it has become an erhu classic that cannot be skipped in the growth process of every erhu player, and has become an erhu. The performers have performed many times, and the music scholars have repeatedly studied the object. "The First Erhu Rhapsody" won the second prize of the 6th National Music Awards (the first prize is vacant). In 2001, "The Second Erhu Rhapsody" won the Silver Award of the 3rd China Music Golden Bell Award (gold medal vacancy). In 2003, "The Third Erhu Rhapsody" won the first prize of the 12th National Music Awards in 2006. In 2009, "The Fourth Erhu Rhapsody" won the first prize at the 15th National Music Awards in 2011. In 2019, "The Fifth Erhu Rhapsody" was selected as the final piece in the 12th Chinese Music "Golden Bell Awards", which astounded the audience, bringing the erhu performance technique and erhu style interpretation to a new peak.

The First Erhu Rhapsody" was created in 1988, and Mr. Wang Jianmin composed it for Deng Jiandong, a senior student at the Nanjing University of the Arts and a young erhu performer. The work won the second prize (the first prize is vacant) in the "Sixth National Music Appraisal Awards" co-sponsored by the Ministry of Culture, the Ministry of Radio, Film and Television and 
the China Music Association.

Nine years after the creation of "The First Erhu Rhapsody", from 1998 to 2001, when it was conceived and completed in 2001, Mr. Wang Jianmin completed the writing of "The Second Erhu Rhapsody". The work was premiered by young erhu performer Deng Jiandong at the Bauhinia Grand Theater in Jiangsu. At the end of 2003, he won the silver medal in the third "Golden Bell Award" National Music Competition (gold medal vacancy).

"The Third Erhu Rhapsody", composed in August 2003, is an erhu work commissioned by Mr. Wang Jianmin for the third highest Chinese music award-the "Golden Bell Award" National Erhu Competition. The composer has grasped some characteristic melodies in Xinjiang tones and developed them as the core materials. In particular, they have absorbed the modal alternation technique in Xinjiang folk songs to make the music rich in national style, the First Prize in Musical Composition Competition". Twenty years after the creation of "The First Erhu Rhapsody", in 2008, at the invitation of the artistic director of the Taipei City Chinese Orchestra, Shao En, Mr. Wang Jianmin composed the "Fourth Erhu Rhapsody" for the 30th anniversary of the Taipei City Chinese Orchestra. As one of the more breakthrough works created by Mr. Wang Jianmin, this work has both Chinese flavor and contemporary style. It became a contestant of the "Seventh Golden Bell Award Folk Music Competition and 2009 China Jiangsu Erhu Folk Music Festival" The designated repertoire is well received by people inside and outside the industry.

The advent of "The Fifth Erhu Rhapsody" represents a new peak for Erhu. In October 2019, the 12th China Music Golden Bell Awards was held in Chengdu. In the final stage of the Golden Bell Award Erhu Competition, as the competitor's compulsory repertoire, Mr. Wang Jianmin was commissioned by the Golden Bell Award Organizing Committee to create "The Fifth Erhu Rhapsody-Hymn", which was astounded by the concert of the Guiyang Symphony Orchestra field.

\section{Aesthetic interpretation of music style}

Among the many music works of Mr. Wang Jianmin, five Erhu Rhapsody is the most representative. These five works were taken from the folk songs of Yunnan-Guizhou area, the characteristic tunes of Hunan folk songs and Huagu Opera, folk songs in Xinjiang, Northwest folk songs and Inner Mongolia long tunes, and combined these materials with their own ideas and modern composition techniques. What's more worthy of recognition is that the five works have continued Mr. Wang Jianmin's original intention for more than 30 years, "not only to write music that can be appreciated by the public, but also to promote the development of the discipline." These works are both Chinese and Western and both refined and popular. They have not only won high praise in the industry, but also have been widely circulated as the compulsory repertoire for national instrumental music competitions at home and abroad, and become an outstanding representative work in the field of national instrumental music creation.

"The First Erhu Rhapsody" is a classic work that Mr. Wang Jianmin integrated and refined based on the elements of Yunnan music in my country. The work adopts a single-movement and multisegment structure in the creative technique. Through the clever use of rhythm and the repetition of alternate three-degree chords, the work vividly expresses the simple folk customs and mystery of the primitive jungles of Yunnan. "The Second Erhu Rhapsody" uses the elements of Hunan folk flower drum opera and folk songs as the original creative materials, with a strong regional and ethnic style. The work is composed of introductions and six sections of music with different speeds but uniform styles. It incorporates a variety of performance techniques and melody, and has a strong modern flavor. "The Third Erhu Rhapsody" depicts the Gobi scenery, inspired by folk music in Xinjiang, full of exotic tones, like a love song singing the charm of Xinjiang. The music of "The Fourth Erhu Rhapsody" is based on the genes of folk songs in the northwest region, which has a 
strong northwestern flavor and a sense of the times. "The Fifth Erhu Rhapsody-Hymn", created in 2019, was awarded by Mr. Wang Jianmin at the 12th Golden Bell Award.

The work commissioned by the Twelfth Golden Bell Awards" Erhu Competition. The composition of this song has been ten years since the last Erhu Rhapsody in the series of Erhu Rhapsody completed in 2009. The same year coincided with New China. The 70th anniversary of the founding of the founding, this song is also a gift to celebrate the 70th birthday of the founding of New China. The music adopts the folk song style of Inner Mongolia as the keynote, with affectionate pen and ink, touching rhyme and beautiful and expressive long tune, which enthusiastically sings the motherland. The magnificent scenery of the earth expresses the author's infinite praise for the motherland.

Compared with the description of the content of title music works, "Rhapsody" tends to be depicted in a regional color, similar to music maps and music geography. China has a vast land and rich folk songs and folk music. Mr. Wang Jianmin tends to create on the large area, presenting rich musical colors. Mr. Wang Jianmin once said: "Chinese style is Chinese style in terms of a big concept, but what really writes is like language. Does it speak Shanghai dialect or Mandarin? Chinese dialects must also have linguistic characteristics." So each of his The works are all from the small to the big, portraying the grandeur of China through the exploration of specific regions.

Mr. Wang Jianmin said in an interview:

"My Erhu Rhapsody series, from the beginning of "The First Erhu Rhapsody", showed the southwestern style, and the regional characteristics are very clear. After writing'Yi Kuang', it actually planted a seed. The "three mads" of madness are written in the color of this regional division. Because China's land is particularly vast, and the folk songs and folk music are particularly abundant. If I am limited to a very small variety and a very small area to write, The music style that may be presented will be relatively simple. So I will adopt the style of color area or geographical area, such as the southwest, northwest or southeast of the motherland, and may also write northeast in the future. Regarding this regional division, famous music The scholar Qiao Jianzhong has a discussion about the division of Chinese folk songs. In fact, Chinese nationalities, different nationalities together or due to different geographical problems, many folk songs in one place have their common characteristics. For example, the folk songs in the northwest, my thinking is in the northwest, not only in Shaanxi.

"The First Erhu Rhapsody" has obvious characteristics in the southwest, because the YunnanGuizhou area is particularly special, and there are many ethnic minorities in the Yunnan-Guizhou area, and each ethnic minority has its own characteristics. This also has its similarities and unique points. So to some extent it is very helpful to our creation. Sometimes you can take a mixed approach to condense the colors or things in an area to form the style you want. In addition, a relatively pure blending method can be adopted to turn the most typical folk music in this area into a language that you want to speak. For example, "The Second Erhu Rhapsody" is a relatively pure tone of Han folk songs. But I designed a composition method that I wanted, designed a scale by myself, blended this feature into it, and enhanced the personal characteristics that I wanted with some intensive and refined writing methods. This is both one This kind of experiment is what I am after. "

\section{Conclusion}

Looking at the five Erhu Rhapsody by Mr. Wang Jianmin, both in terms of ideology and creative techniques, it not only maintains the national characteristics, but also demonstrates the distinctive creative personality.

The five works are all named after the Western genre "Rhapsody", which reflects Mr. Wang 
Jianmin's strong desire to break through the narrative, descriptive, and single-material characteristics of traditional Chinese instrumental music. With this freedom of music structure, the paragraphs and themes are flexible and changeable, the sense of restraint is small, and the genre with great space is used to broaden the possibilities of creation, while retaining some of the structural characteristics of traditional Chinese genres. The musical structure of single movement and multi-segment style, the introduction and the connection between the paragraphs are completed by scattered boards. The loose board is a typical structural feature of Chinese music. Whether it is enlightenment, transition or promotion, it makes each segment of the multi-segment structure coherent and natural, and achieves an integrated effect.

The role of anxious board is to push the music to a climax, so that the emotions that have been laid before can be quickly vented, which is again a typical structural feature of Western Rhapsody. Mr. Wang Jianmin has found a good fusion point in the structure of Chinese and Western genres. The music has made extremely creative efforts and explorations in the development of erhu performance techniques, musical vocabulary performance and composition techniques. In Wang Jianmin's series of rhapsody works, we can clearly see his conscious pursuit of aesthetic modernity.

"In the beginning, when I considered using Rhapsody, one of the most important points was the diversity of its musical styles. Rhapsody is generally multi-stage, which just happens to have a certain similarity with the multi-tune cards of our Chinese folk music. There is also a very important point, Rhapsody. It shows a certain real-time characteristic that the previous folk music did not have. This is also my specific method of promoting folk music and showing the grandeur of Chinese culture. In addition, untitled is also a consideration. Traditional music has been too innovative for a period of time. Pay attention to the title. In fact, there are many untitled tracks that convey spiritually and do not lose to the titled works, because they provide people with greater imagination. In the final stage of the Golden Bell Awards, the contestants played the "Five Crazy "Hey turn the audience, I just want to create this kind of momentum, I just want to give people a feeling: Erhu is not an earthen musical instrument, it can exert tremendous energy."

\section{References}

[1] Qiao Jianzhong. (2000). A musical instrument and a century - - A century-old view of Erhu art. Music Research, 2000(01), 36-44.

[2] Qiao Jianzhong. (2017). Tradition, modernity and others-Deng Jiandong's piano sound. People's Music: Critic Edition, 2017 (08), 4-8.

[3] Qiao Jianzhong. (2011). On the modern spirit of erhu art. People's Music: Critic Edition, 2011 (05), 46-49, 95-96.

[4] Wang Jianmin. (2014). Composing new national rhymes and expressing Chinese feelings_-Review and reflection on the creation of "The First Erhu Rhapsody". People's Music, 2014 (03), 31-34.

[5] Wang Jianmin. (2003). Originated from folk root system tradition-"The Second Erhu Rhapsody" creation notes. People's Music, 2003(09), 2-5.

[6] Wang Jianmin. (2000). The study of melody. People's Music, 2000(2), 13-17.

[7] Wang Jianmin. (1999). On melody progression-a series of papers on melody. Journal of Nanjing University of the Arts (Music and Performance Edition), 1999(01), 3-12.

[8] Kong Zhixuan. (2020). A contemporary hymn from the grassland-Wang Jianmin's "The Fifth Erhu Rhapsody" Creation Comment. People's Music, 2020(6).

[9] Cheng Lin. (2019, November 25). Looking for "Crazy" Forward--A Comment on Wang Jianmin's Erhu Rhapsody. China Art News, No. 005, Hundred Schools of Art.

[10] Zhu Weiting. (2017). An analysis of the creative characteristics of Wang Jianmin's "The Second Erhu Rhapsody". Music creation, 2017(2), 129-131.

[11] Chen Chunyuan. (2017). Wang Jianmin's "Erhu Rhapsody Series" fingering application analysis and related thinking. People's Music, 2017(10), 38-41.

[12] Ru Yi. (2007). On the significance of Wang Jianmin's erhu works to the development of erhu art. (Doctoral dissertation, Shanghai Conservatory of Music).

[13] Ru Yi. (2008). From Wang Jianmin's Erhu Rhapsody to see his creative ideas and musical characteristics. Chinese 
Music, 2008(03), 219-221.

[14] Ru Yi. (2007). On the significance of Wang Jianmin's erhu works to the development of erhu art. Shanghai: Shanghai Conservatory of Music Press.

[15] Ru Yi. (2008). Wang Jianmin's Erhu Rhapsody Creation and Performance Analysis__Also on the innovative development of contemporary Erhu performance technology. Huang Zhong-Journal of Wuhan Conservatory of Music, 2008(04), 162-169.

[16] Zhang Yue. (2019, December 13). From "one madness" to "five madness", enhance the quality of erhu and show Chinese style. China Art News.

[17] Zhang Lei. Thoughts on the artistic characteristics and second creation of Wang Jianmin's "The Fourth Erhu Rhapsody". (Doctoral dissertation, China Conservatory of Music).

[18] Qian Renping, Tang Rong. (2013). Chinese breath, characteristics of the times-Wang Jianmin's "Erhu Rhapsody" creation. Chinese Music, 2013(003), 57-60.

[19] Qi Ping. (2005). Music performance art: theory and practice. Beijing: People's Music Publishing House. 